\title{
VOLTAGE STABILITY ANALYSIS IN AN IEEE 34 NODES TEST SYSTEM WITH THE PARTICIPATION OF PHOTOVOLTAIC GENERATION PLANTS
}

\section{VÍCTOR HUGO MEDINA GARCÍA ${ }^{1}$, RIVAS TRUJILLO, EDWIN ${ }^{2} \&$ RAMÍREZ VANEGAS CARLOS $^{3}$}

${ }^{1}$ Facultad de Ingeniería, Universidad Distrital Francisco José de Caldas, Bogotá D.C., Colombia

${ }^{2}$ Facultad de Ingeniería, Universidad Distrital Francisco José de Caldas, Bogotá D.C. 11021, Colombia; Grupo de Investigación GCEM

${ }^{3}$ Departamento de Matemáticas, Universidad Tecnológica de Pereira, Pereira, Colombia

\section{ABSTRACT}

This article describes a stability analysis in critical and generation nodes for an IEEE 34 topology that contains photovoltaic generation plants. The case studies the participation of photovoltaic plants is shown with 15\% total generation of the system. The purpose of the case studies is to determine the range of stability that can be accepted in the proposed topology with the penetration of photovoltaic generation of the $15 \%, 25 \%$ and $50 \%$, as well as to present the possible voltage variations, power drops and change in rotor angles in existing synchronous machines in the topology, in steady state as at the time of a failure.

KEYWORDS: DIGSILENT, Generation, Photovoltaic Plant

Received: Oct 10, 2020; Accepted: Oct 30, 2020; Published: Nov 09, 2020; Paper Id.: IJMPERDOCT202030

\section{INTRODUCTION}

For the development of the analysis, the test topology 34 IEEE nodes is used (Figure 1).

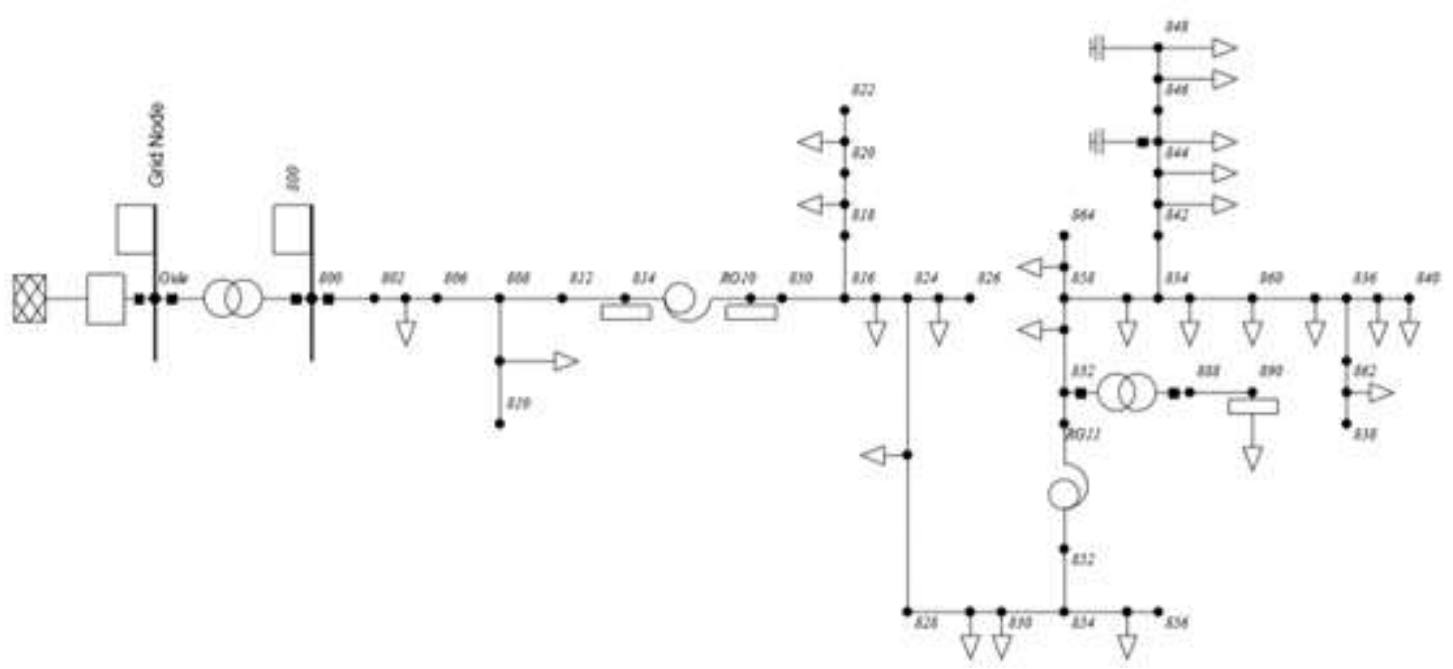

Figure 1: IEEE 34 Node Test Topology [1]

When creating this configuration in the DIGSILENT software, adding virtual generation plants in some nodes and defining the nodes as bars with real impedance parameters and connection points, a much more voluminous scheme is obtained that is presented in figure 2, this it is attached in a legible format in the annexes to 
this report.

All the elements of the proposed network were implemented in the DIGSILENT software, as an example shown in figure 3, the transformers between the bus 832-888 and the autotransformers between the bars 814-850.

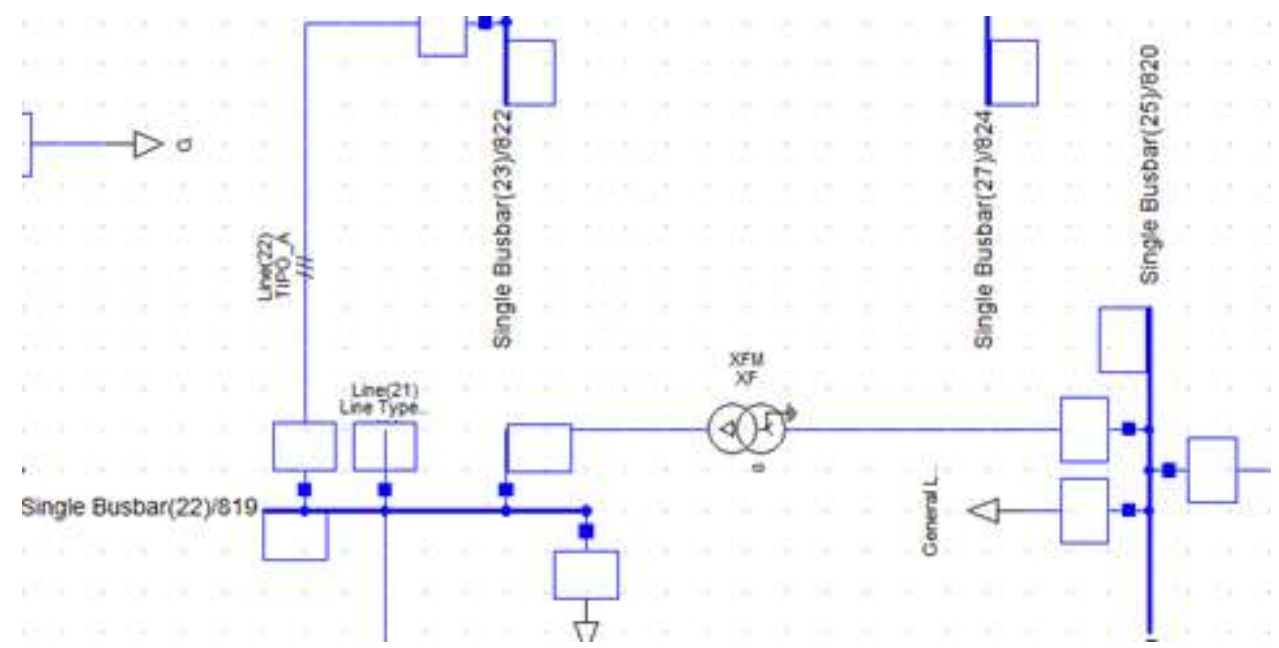

Figure 3: Detail of elements in implemented topology (Created by the authors)

The line impedance parameters are shown in table 1 , the impedance configuration in the lines is shown in table 2 .

The voltage values in the different nodes are given by the system transformers, for the present case two voltages are presented, $24.9 \mathrm{kV}$ and $4.16 \mathrm{kV}$, other parameters of these transformers are presented in table 3 and figure 4 .

Table 1: Data line segments IEEE network 34

\begin{tabular}{|l|l|l|l|}
\hline $\begin{array}{c}\text { Node } \\
\text { A }\end{array}$ & $\begin{array}{c}\text { Node } \\
\text { B }\end{array}$ & Length(ft.) & Config \\
\hline 800 & 802 & 2580 & 300 \\
\hline 802 & 806 & 1730 & 300 \\
\hline 806 & 808 & 32230 & 300 \\
\hline 808 & 810 & 5804 & 303 \\
\hline 808 & 812 & 37500 & 300 \\
\hline 812 & 814 & 29730 & 300 \\
\hline 814 & 850 & 10 & 301 \\
\hline 816 & 818 & 1710 & 302 \\
\hline 816 & 824 & 10210 & 301 \\
\hline 818 & 820 & 48150 & 302 \\
\hline 820 & 822 & 13740 & 302 \\
\hline 824 & 826 & 3030 & 303 \\
\hline 824 & 828 & 840 & 301 \\
\hline 828 & 830 & 20440 & 301 \\
\hline 830 & 854 & 520 & 301 \\
\hline 832 & 858 & 4900 & 301 \\
\hline 832 & 888 & 0 & $\begin{array}{l}\text { XFM- } \\
1\end{array}$ \\
\hline 834 & 860 & 2020 & 301 \\
\hline 834 & 842 & 280 & 301 \\
\hline 836 & 840 & 860 & 301 \\
\hline 836 & 862 & 280 & 301 \\
\hline 842 & 844 & 1350 & 301 \\
\hline 844 & 846 & 3640 & 301 \\
\hline 846 & 848 & 530 & 301 \\
\hline & & & \\
\hline
\end{tabular}




\begin{tabular}{|l|l|l|l|}
\hline 850 & 816 & 310 & 301 \\
\hline
\end{tabular}

Table 2: Impedance settings for some of the implemented lines

\begin{tabular}{|c|c|c|c|c|c|}
\hline \multicolumn{7}{|c|}{ Z \& B Matrices before Changes } \\
\hline \multicolumn{7}{|c|}{ Z (R + jX in ohms per mile) } \\
\hline 1.3368 & 1.3343 & 0.2101 & 0.5779 & 0.2130 & 0.5015 \\
\hline & & 1.3238 & 1.3569 & 0.2066 & 0.4591 \\
\hline & & & 1.3294 & 1.3471 \\
\hline \multicolumn{7}{|c|}{ B in micro Siemens per mile } \\
\hline \multicolumn{2}{|c|}{-1.5313} & -0.9943 \\
\hline \multicolumn{2}{|c|}{5.0979} & -0.6212 \\
\hline
\end{tabular}

Table 3: Transformers parameters

\begin{tabular}{|l|l|l|l|l|l|}
\hline & \multicolumn{1}{|c|}{ kVA } & \multicolumn{1}{|c|}{ kV-high } & \multicolumn{1}{c|}{ kV-low } & \multicolumn{1}{|c|}{ R-\% } & \multicolumn{1}{|c|}{} \\
\hline Substation & 2500 & $69-\mathrm{D}$ & $24.9-$ Gr. W & 1 & 8 \\
\hline XFM -1 & 500 & $24.9-$ Gr. W & $4.16-$ Gr.W & 1.9 & 4.08 \\
\hline
\end{tabular}

2-Winding Transformer Type - Equipment Type Library \rafo1.TypTr2

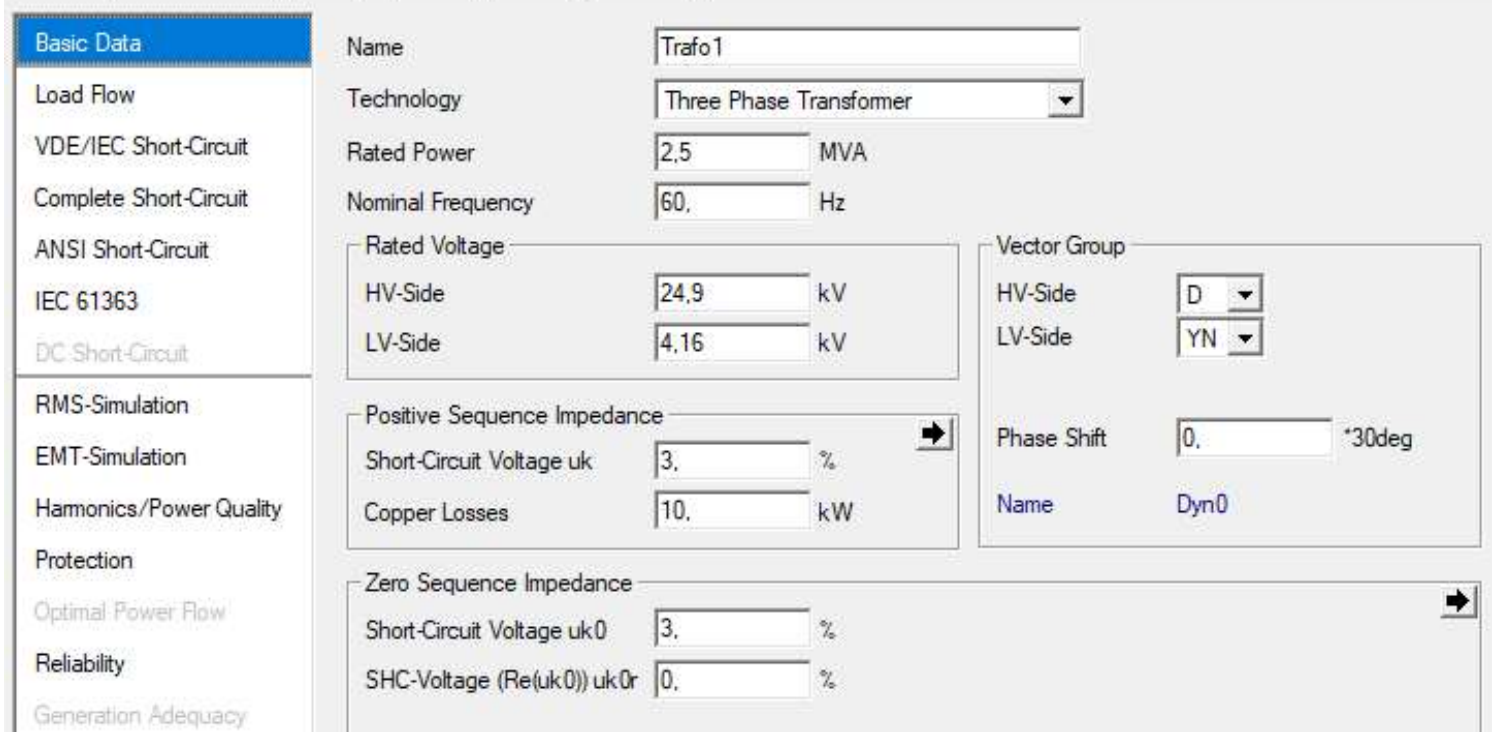

Figure 4: "Substation" transformer parameters in implemented scheme.

\section{PARAMETERS OF THE PHOTOVOLTAIC PLANT}

The parameters of apparent nominal power, power factor, number of inverters, active and reactive power limits, internal resistance of the element, maximum current, minimum voltage disconnection, disconnection time, among others, are presented in table 4 . 
Table 4: Virtual power plant parameters

\begin{tabular}{|l|l|}
\hline \multicolumn{1}{|c|}{ Technology } & \multicolumn{1}{c|}{ Three-phase active power source } \\
\hline Number of inverters in parallel & one \\
\hline Nominal apparent power & $100 \mathrm{kVA}$ (Variable in stability tests) \\
\hline Power factor & 0.8 (Inductive) \\
\hline Active power upper and lower limits & $0-9999 \mathrm{~kW}$ \\
\hline Short circuit model & Dynamic Voltage \\
\hline Investor internal losses & $0.8 \%$ \\
\hline Internal control model & Voltage level (+ or-) $10 \%$ \\
\hline
\end{tabular}

The generation curves are those presented in [1], shown in table 5, figure 5 and figure 6.

Table 5: Model proposed for photovoltaics for 24 hours (taken from proposed article [1]).

\begin{tabular}{|l|l|}
\hline Hour & $\begin{array}{l}\text { Power } \\
\text { on FV }\end{array}$ \\
\hline $0: 00$ & 0 \\
\hline $1: 00$ & 0 \\
\hline $2: 00$ & 0 \\
\hline $3: 00$ & 0 \\
\hline $4: 00$ & 0 \\
\hline $5: 00$ & 0 \\
\hline $6: 00$ & 10 \\
\hline $7: 00$ & 40 \\
\hline $8: 00$ & 60 \\
\hline $9 ; 00$ & 80 \\
\hline $10: 00$ & 90 \\
\hline $11: 00$ & 95 \\
\hline $12: 00$ & 100 \\
\hline $13: 00$ & 100 \\
\hline $14: 00$ & 98 \\
\hline $15: 00$ & 95 \\
\hline $16: 00$ & 75 \\
\hline $17: 00$ & 50 \\
\hline $18: 00$ & 30 \\
\hline $19: 00$ & 10 \\
\hline $20: 00$ & 0 \\
\hline $21: 00$ & 0 \\
\hline $22: 00$ & 0 \\
\hline $23: 00$ & 0 \\
\hline & \\
\hline
\end{tabular}

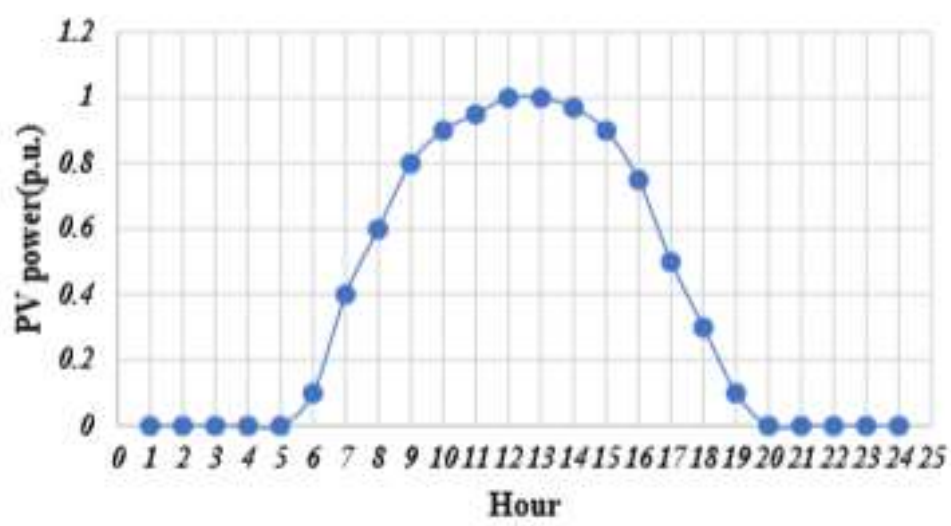

Figure 5: Model curve proposed for photovoltaics for 24 hours (taken from proposed article [1]). 


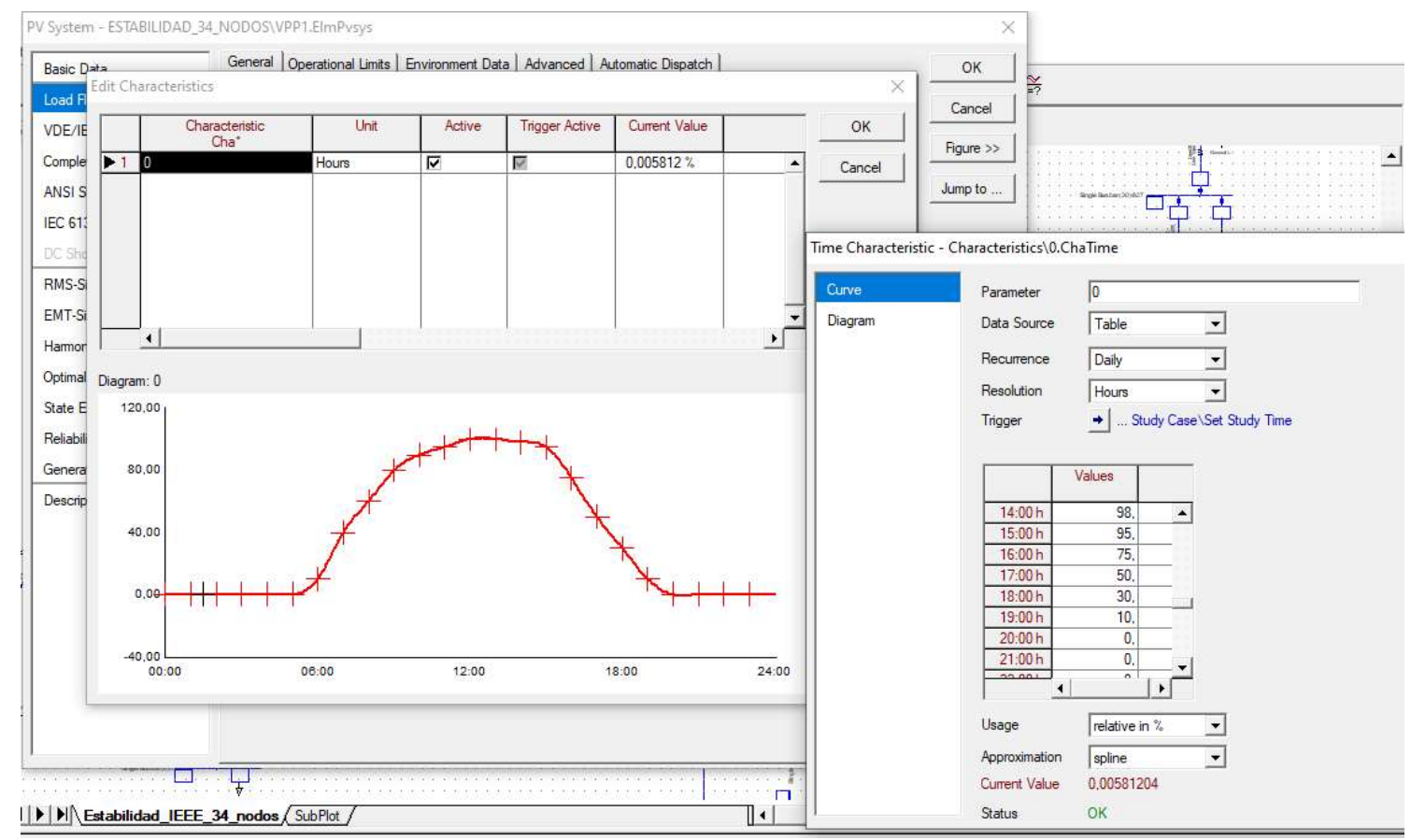

Figure 6: Generation curve in DigSilent interface. (Own elaboration of the authors)

\subsection{Demand Data}

For the generation of the load vectors for each hour of a day, a random of 34 values of consumed power is made, one for each node, which meet the condition that their sum must be the total power available in that hour given all the generators and all the PHOTOVOLTAIC PLANT, their condition is given by the following function.

$\frac{\text { Random for current node }}{\text { (add 34 random } * \text { maximum allowable load value in that hour) }}$

This calculation is made for each node and for each hour, resulting in a matrix of $24 * 34$ values, which are shown in table 6 .

Table 6: Representation of vector matrix generated per hour

\begin{tabular}{|l|l|l|l|l|l|l|l|l|}
\hline Hour & $\begin{array}{c}\text { Loading } \\
\text { Vector }\end{array}$ & Node 800 & Node 801 & Node 802 & Node 803 & Node 804 & Node 805 & Node BB \\
\hline $00: 00$ & 700 & 31.23160748 & 10.5944433 & 16.20221696 & 39.9404844 & 21.8221115 & 37.8175748 & 15.9502471 \\
\hline $01: 00$ & 802 & 35.78249886 & 12.13820504 & 18.56311143 & 45.76038356 & 25.0019049 & 43.3281357 & 18.2744259 \\
\hline $02: 00$ & 670 & 29.89311002 & 10.14039573 & 15.50783623 & 38.22874935 & 20.8868781 & 36.1968216 & 15.266665 \\
\hline $03: 00$ & 730 & 32.57010494 & 11.04849087 & 16.89659769 & 41.65221945 & 22.7573448 & 39.438328 & 16.6338291 \\
\hline $04: 00$ & 650 & 29.00077837 & 9.837697351 & 15.04491575 & 37.08759266 & 20.2633892 & 35.1163194 & 14.8109437 \\
\hline $05: 00$ & 850 & 37.9240948 & 12.86468115 & 19.67412059 & 48.49915963 & 26.4982782 & 45.9213408 & 19.3681571 \\
\hline
\end{tabular}




\begin{tabular}{|l|l|l|l|l|l|l|l|l|}
\hline $06: 00$ & 900 & 40.1549239 & 13.6214271 & 20.83142181 & 51.35205137 & 28.0570005 & 48.6225961 & 20.5074605 \\
\hline $07: 00$ & 910 & 40.60108972 & 13.77277629 & 21.06288205 & 51.92262972 & 28.3687449 & 49.1628472 & 20.7353212 \\
\hline $08: 00$ & 870 & 38.81642644 & 13.16737953 & 20.13704108 & 49.64031633 & 27.1217671 & 47.0018429 & 19.8238785 \\
\hline $09: 00$ & 950 & 42.38575301 & 14.37817305 & 21.98872302 & 54.20494312 & 29.6157227 & 51.3238515 & 21.6467639 \\
\hline $10: 00$ & 1100 & 49.07824033 & 16.6484109 & 25.46062665 & 62.76361834 & 34.2918895 & 59.4276175 & 25.064674 \\
\hline $11: 00$ & 1110 & 49.52440615 & 16.79976009 & 25.69208689 & 63.33419669 & 34.6036339 & 59.9678685 & 25.2925346 \\
\hline $12: 00$ & 920 & 41.00472556 & 13.92412548 & 21.29434229 & 52.49320807 & 28.6804894 & 49.7030983 & 20.9631819 \\
\hline $13: 00$ & 810 & 36.13943151 & 12.25928439 & 18.74827962 & 46.21684623 & 25.2513004 & 43.7603365 & 18.4567145 \\
\hline $14: 00$ & 850 & 37.9240948 & 12.86468115 & 19.67412059 & 48.49915963 & 26.4982782 & 45.9213408 & 19.3681571 \\
\hline $15: 00$ & 930 & 41.49342137 & 14.07547467 & 21.52580253 & 53.06378642 & 28.9922338 & 50.2433493 & 21.1910425 \\
\hline
\end{tabular}

Table 7 shows the values on which the load vector matrix depends.

Table 7: Values on which the charge vector matrix depends

\begin{tabular}{|l|l|l|l|l|l|}
\hline \multirow{3}{*}{34 IEEE Node Network } & \multicolumn{5}{|l|}{ Maximum power available by VPP generators } \\
\cline { 2 - 7 } & Zone 1 -> & Generator 1 & 600 & N/A & 0 \\
\cline { 2 - 7 } & Zone 2 -> & Generator 2 & 600 & VPP1 & 75 \\
\cline { 2 - 7 } & Zone 3 -> & Generator 3 & 600 & VPP2 \& VPP3 & 225 \\
\hline
\end{tabular}

To exemplify in detail, figure 7 shows the power consumed by nodes in a 24 -hour period.

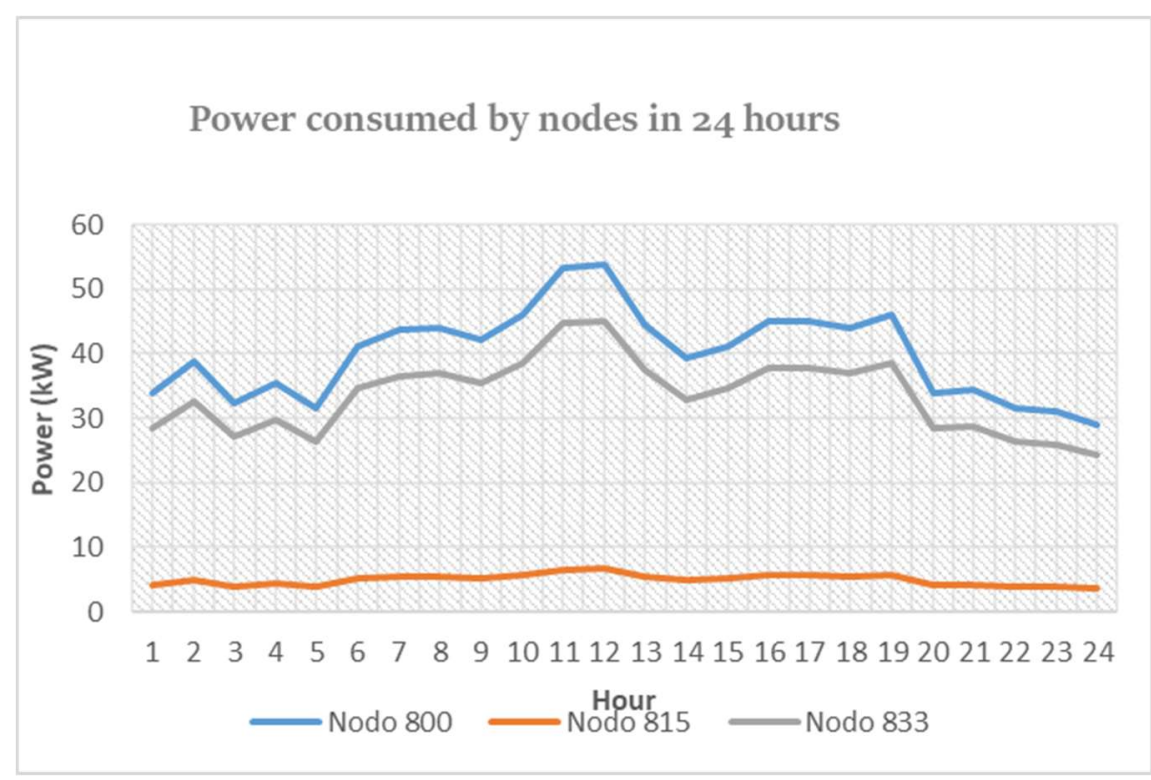

Figure 7: Power consumed by reference nodes in 24 hours 


\section{PERMISSIBLE LIMITS OF VOLTAGE AND LOADABILITY OF THE NODES}

Figure 8 shows the status of each node and each generator of the network according to the proposed limits. Although this graphic form is efficient to represent the conditions in which all the elements of the system are found, it does not allow to determine the variations and overloads that the generators present, therefore, it is necessary to generate a report of voltages, active and reactive power, current and load percentage of all bars for each hour, and analyze each generator independently for 24 hours.

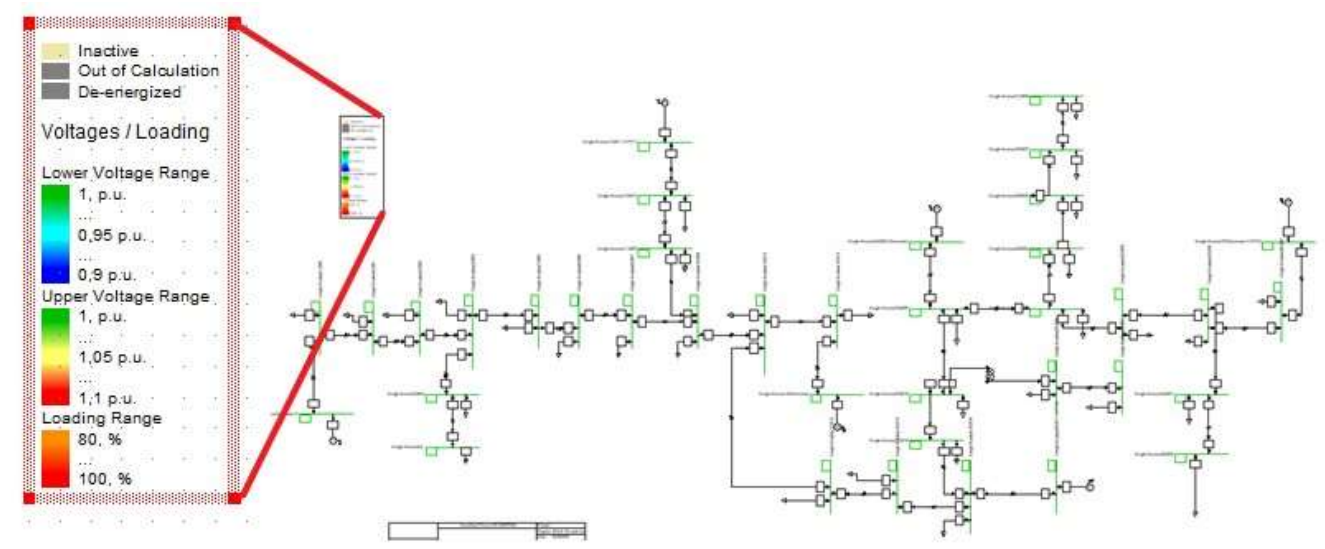

Figure 8: Detail of permissible limits of voltage and chargeability in network nodes.

Figure 9 shows the demand vector taken as a reference for the respective analysis of the IEEE 34 node power system.

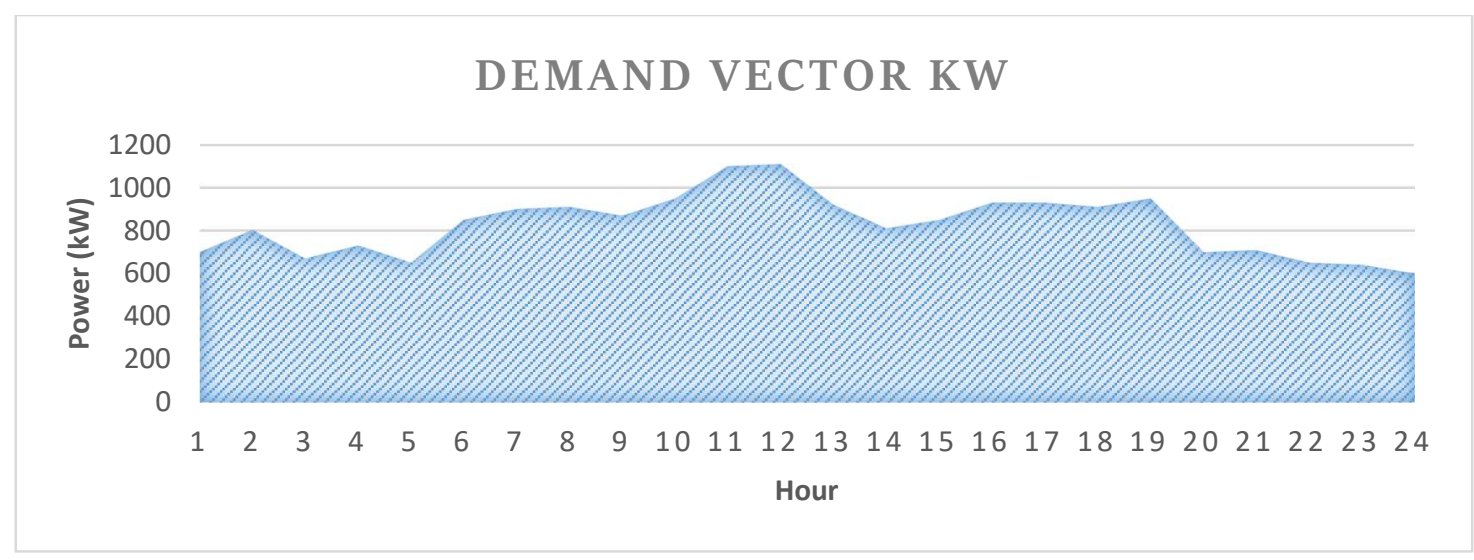

Figure 9: 24-hour demand vector.

In the simulation there are six generators distributed as follows: three conventional generators and three unconventional (PHOTOVOLTAIC PLANT), it is observed in the graph of figure 10 that the power generated by conventional generators (G1, G2, G3) and the non-conventional ones (photovoltaic plant1, photovoltaic plant2, photovoltaic plant3) correctly supply the energy demanded with small variations due to losses of transmission lines. 


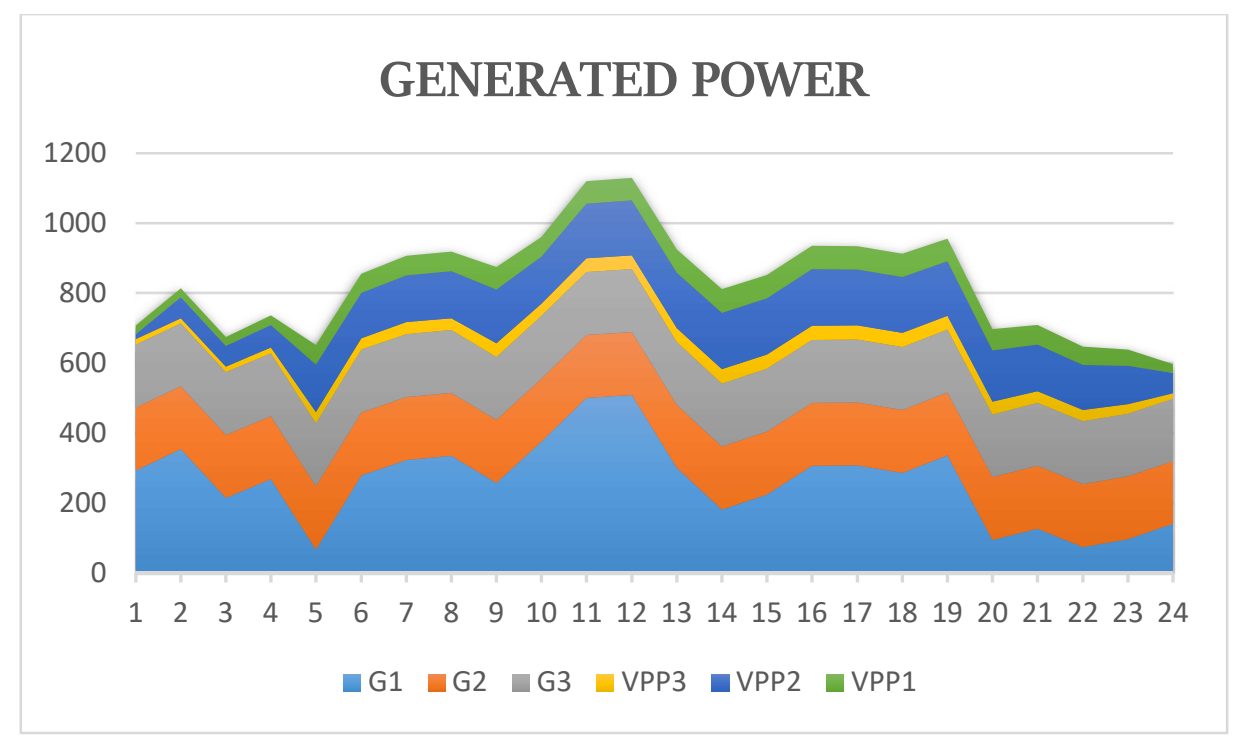

Figure 10: Based on this power flow and the generated demand curves, we have the highest and lowest demand hours, as well as the critical nodes of the system (Table 8).

Table 8: Maximum and minimum powers in 24 hours and critical node of the system

\begin{tabular}{|c|c|}
\hline Power $(\mathrm{kW})$ at peak time $(12: 00)$ & Power $(\mathrm{kW})$ in hour of least demand $(24: 00)$ \\
\hline 1130 & 597 \\
\hline Critical node of the system at peak time & Node 890 \\
\hline
\end{tabular}

Finally, it is determined that the stability analysis must be carried out at the critical node of the system (Node 890 ) since it is the furthest from the reference node (node 800), then a three-phase fault and stability analysis is performed at this point, varying the generation penetration of the PHOTOVOLTAIC PLANT by $15 \%$.

\section{STABILITY ANALYSIS WITH 15\% PARTICIPATION OF PHOTOVOLTAIC PLANT}

To perform the stability analysis in this case, the power that each generator node must have is determined, for a $15 \%$ share of the photovoltaic plants (Table 9).

Table 9: Power to be generated by each node in participation of $15 \%$ of the PHOTOVOLTAIC PLANT

\begin{tabular}{|l|l|}
\hline \multicolumn{2}{|l|}{ Case 1 Photovoltaic plants with $15 \%$ participation } \\
\hline \multicolumn{1}{|c|}{ Generator } & \multicolumn{1}{c|}{ Power $(\mathbf{k W})$} \\
\hline Gen 1 & 360 \\
\hline Gen 2 & 300 \\
\hline Gen 3 & 300 \\
\hline
\end{tabular}




\begin{tabular}{|l|l|}
\hline Vpp1 & 60 \\
\hline Vpp2 & 100 \\
\hline Vpp3 & 10 \\
\hline Total Power & 1130 \\
\hline
\end{tabular}

When a three-phase fault occurs, the voltage of the shorted node falls, while the voltages of the other nodes and generators also fall, but it recovers when the protections are activated, although not instantaneously, as illustrated in figure 11.

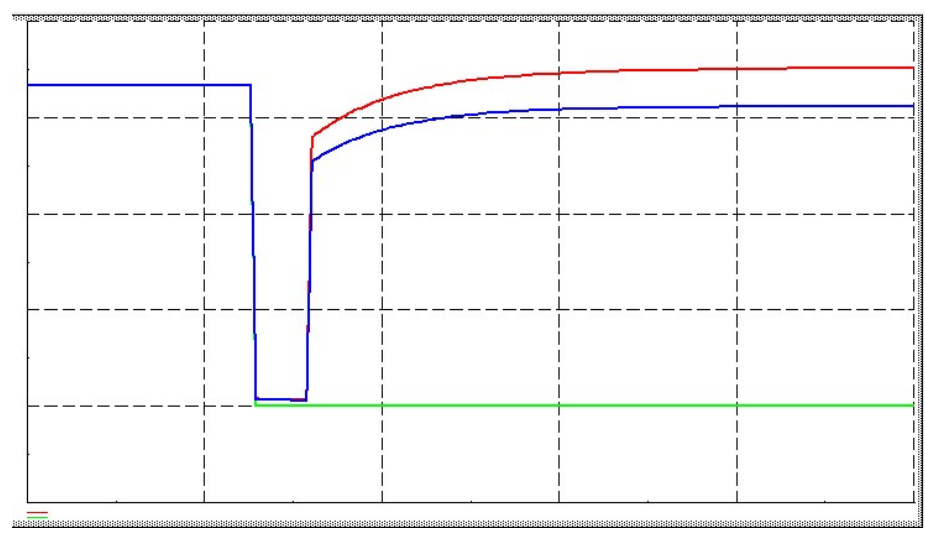

Figure 11: Voltage per unit in Fault Node (Green) Conventional plants (red) and PHOTOVOLTAIC PLANT (Blue)

The data obtained for the rotor angle of a synchronous generator (node 800 - Blue line) and the power factor of photovoltaic plants is described in figure 12, which shows how the rotor angle becomes unstable given the fault, and It tends to stabilize over time, while the power factor of photovoltaic plants recovers immediately when the switches are opened, to fall over time given the instability and overload of the system in it.

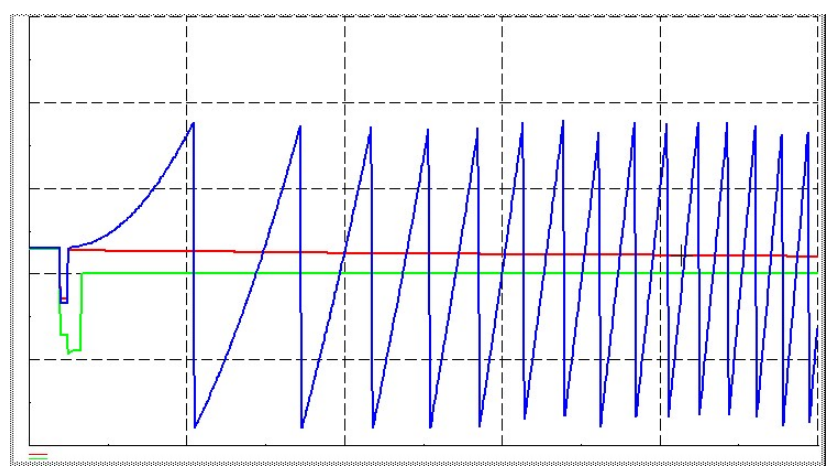

Figure 12. Node 800 generator rotor angle in radians and power factor of plants fotovoltaicas.

In the fault bus, the voltage and current per unit are calculated to check the estimated behavior, the voltage decreases and the current rises abruptly, until the time in which the protection trips, dissipating the fault, this is shown in the figure 13, the red line being the voltage, and the blue line being the current. 


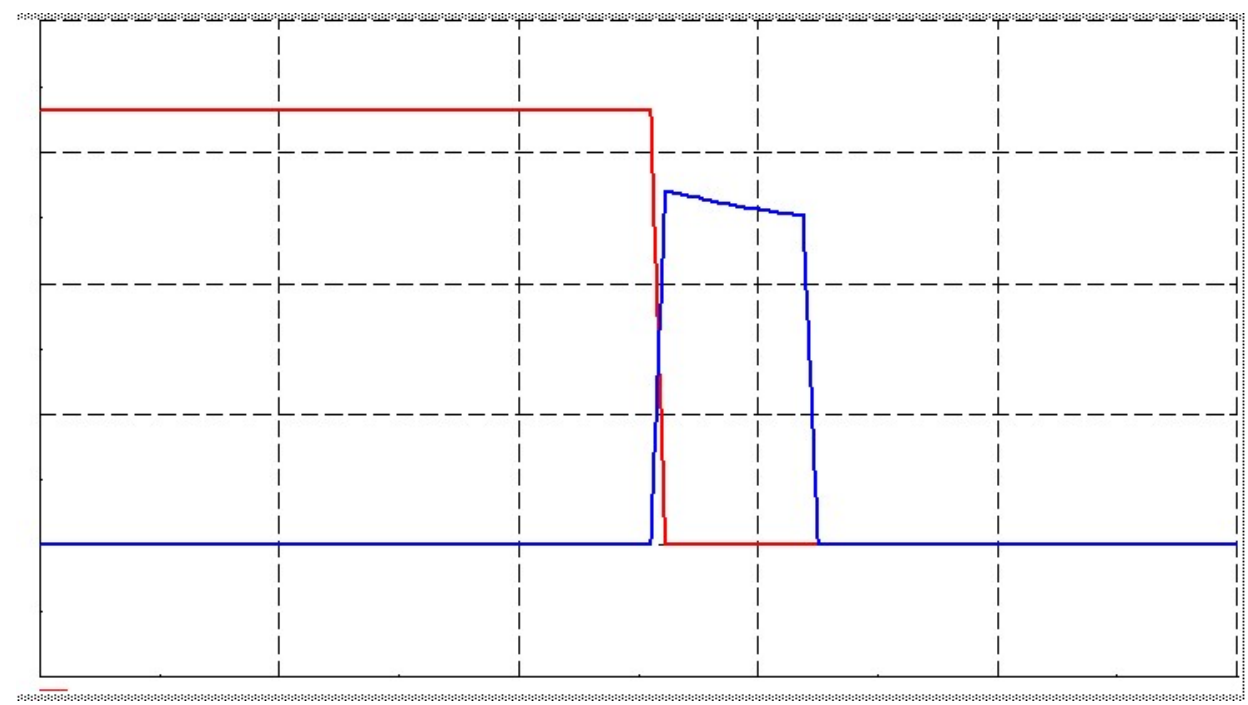

Figure 13: Current (blue line) and voltage (red line) at the fault node.

The voltages in the generation nodes remain relatively stable at the time of failure, they decrease from their value 1 per unit to 0.2 per unit, to gradually stabilize after the opening of the protection contacts in a time of 0.2 seconds, sufficient to ensure the stability of the system.

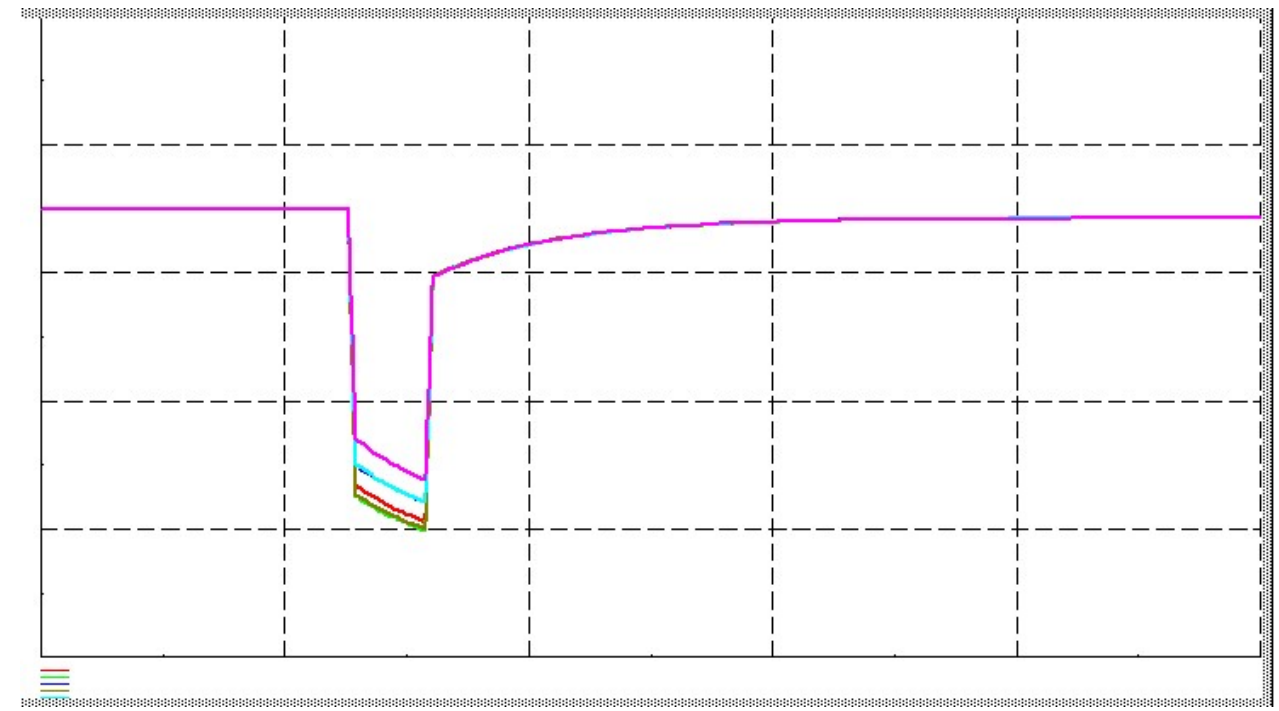

Figure 14: Voltages in generating bars during failure.

The power delivered by the generating nodes grows 2.3 times at the moment of the failure, to fall when it dissipates, however, the time required to achieve coordination in generation is 0.5 seconds, considerable, although it does not present a risk for the physical components of these elements ( figure 15). 


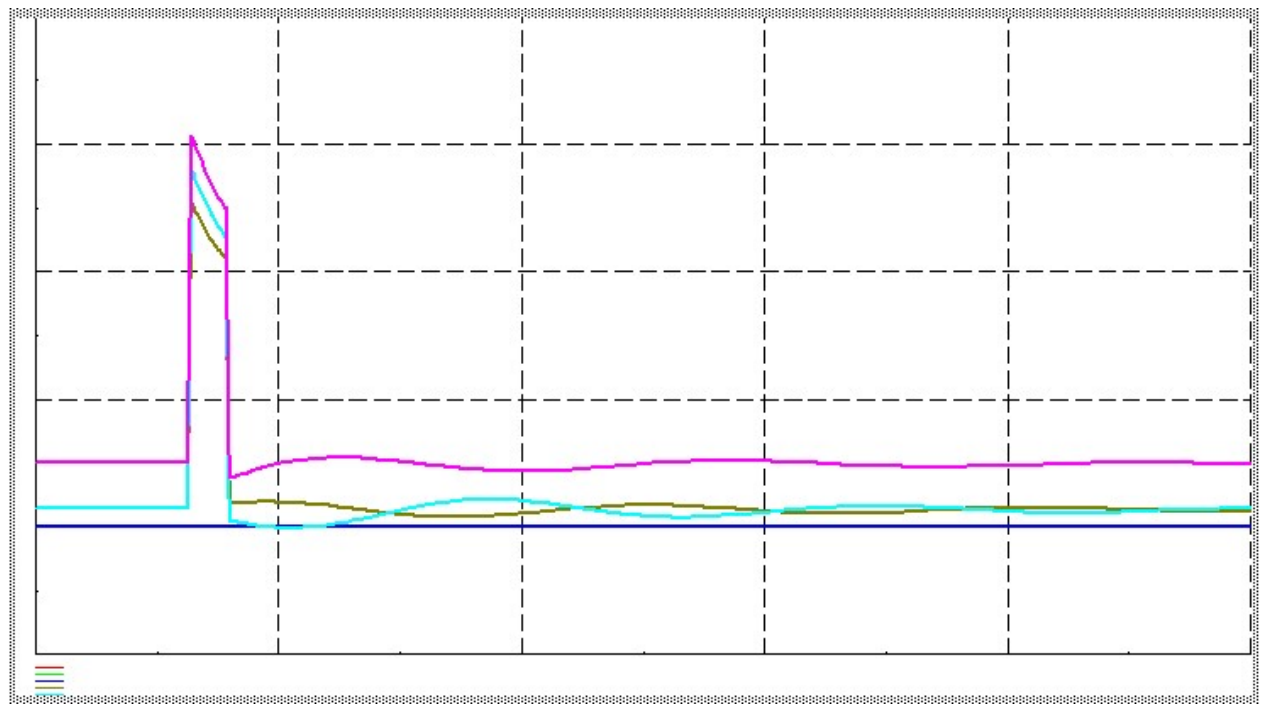

Figure 15: Active power in generator nodes at failure time.

The power factor in the generating nodes varies enormously depending on their location in the topology, that is, how far away from the point of failure they are, in figure 16 we have the furthest node (ocher line - node 800 ) presents a slight variation of its power factor, while virtual plant 2 (celestial line - node 824) presents an enormous variation given its proximity and little resistance to failure ( figure 16).

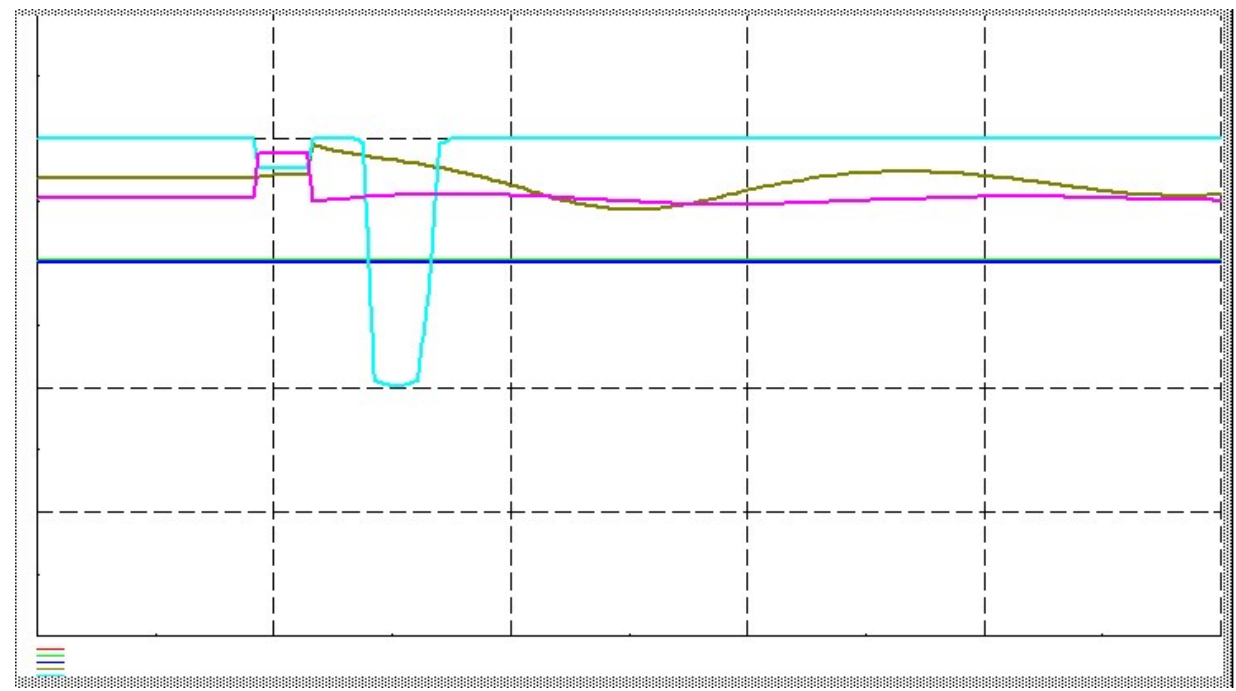

Figure 16: Power factor in system generation nodes

For a more detailed analysis of the condition of distance to failure, the variation of the rotor angle of the generators implemented in the topology is analyzed, for a long distance the impact on the machine is minimal, as evidenced by the yellow line in the following graph, while the blue and red lines represent synchronous machines close to the point of failure, showing greater disturbance in their torque and angle of rotation ( figure 17). 


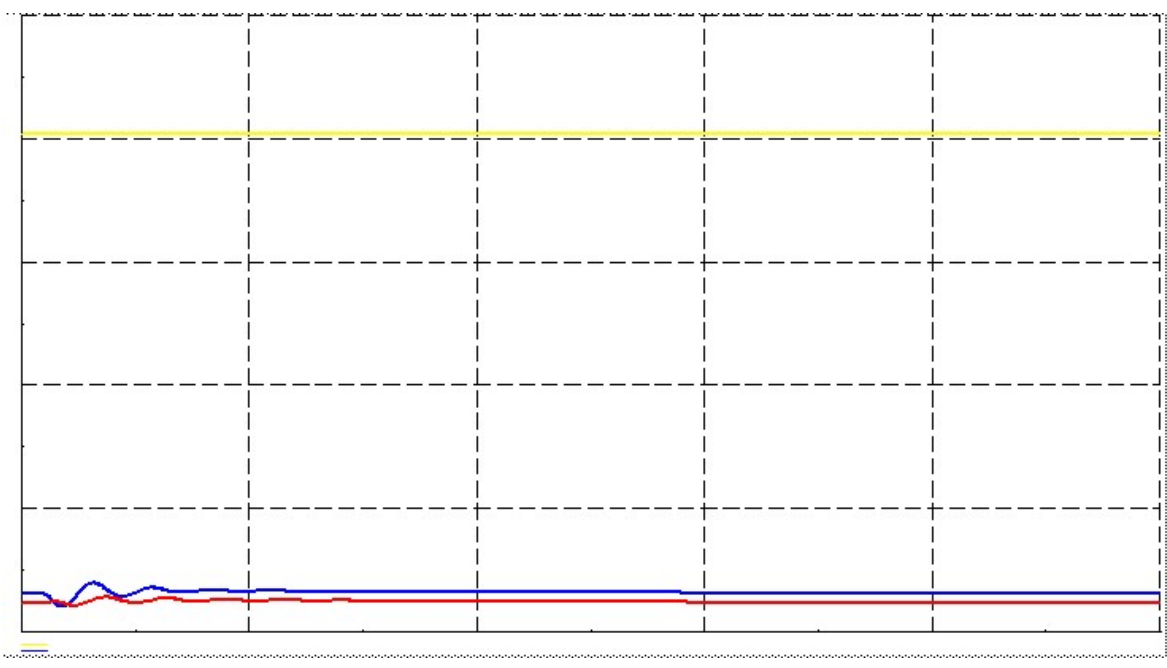

Figure 17: Rotor angle during failure of synchronous generators of the system.

\section{RESULTS}

Results with case $1-15 \%$ partition of PHOTOVOLTAIC PLANT.

Voltage in Generators G1, G2, G3, Photovoltaic Plant1, Photovoltaic Plant2, Photovoltaic Plant3 with t $=0.5 \mathrm{~s}$ ( figure 18).

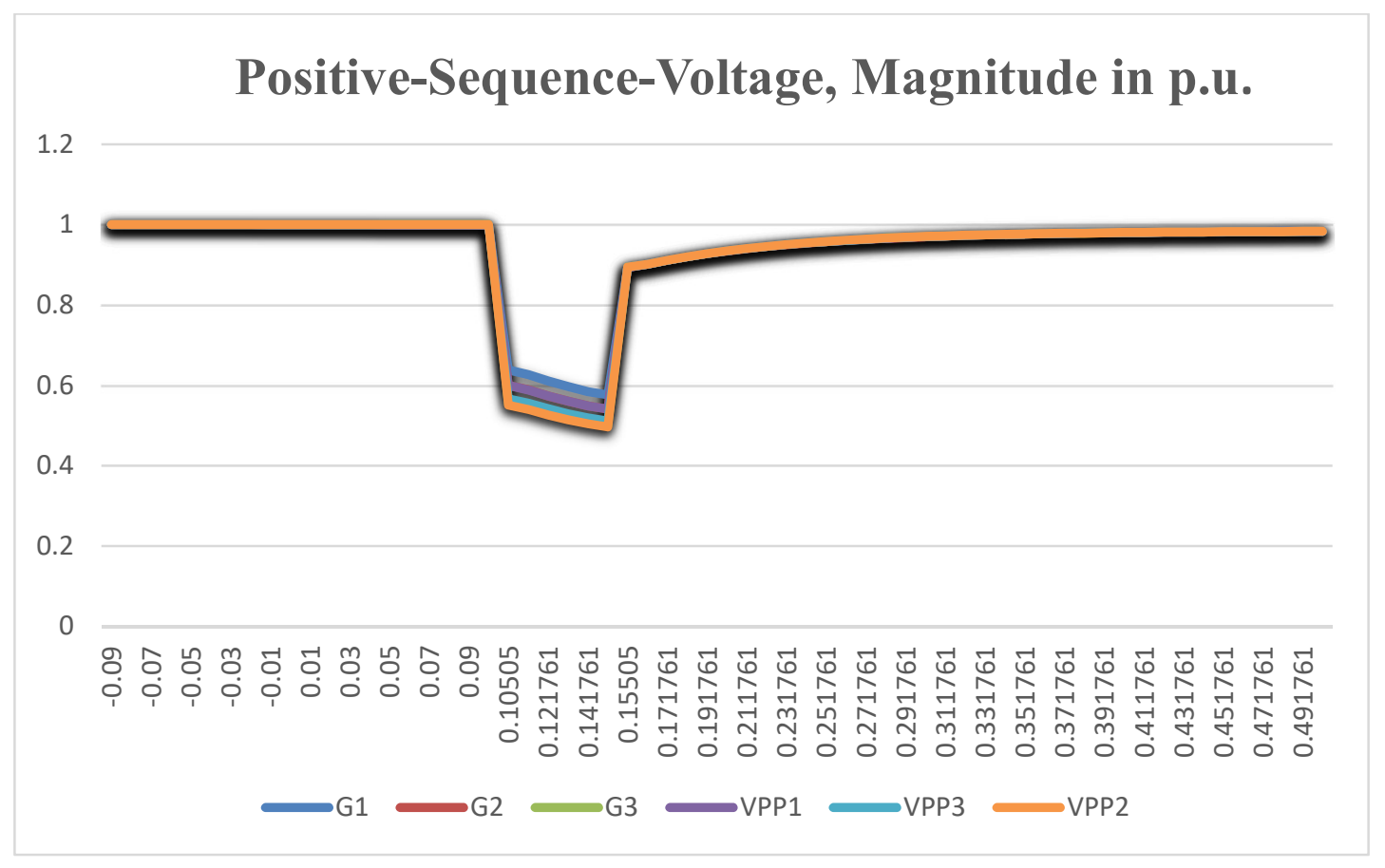

Figure 18: Voltage in Generators G1, G2, G3, Photovoltaic Plant1, Photovoltaic Plant2, Photovoltaic Plant3 with t= 0.5s.

Active power in generators G1, G2, G3, PHOTOVOLTAIC PLANT1, PHOTOVOLTAIC PLANT2 AND PHOTOVOLTAIC PLANT3 with a $\mathrm{t}=0.6 \mathrm{~s}$ ( Figure 19). 


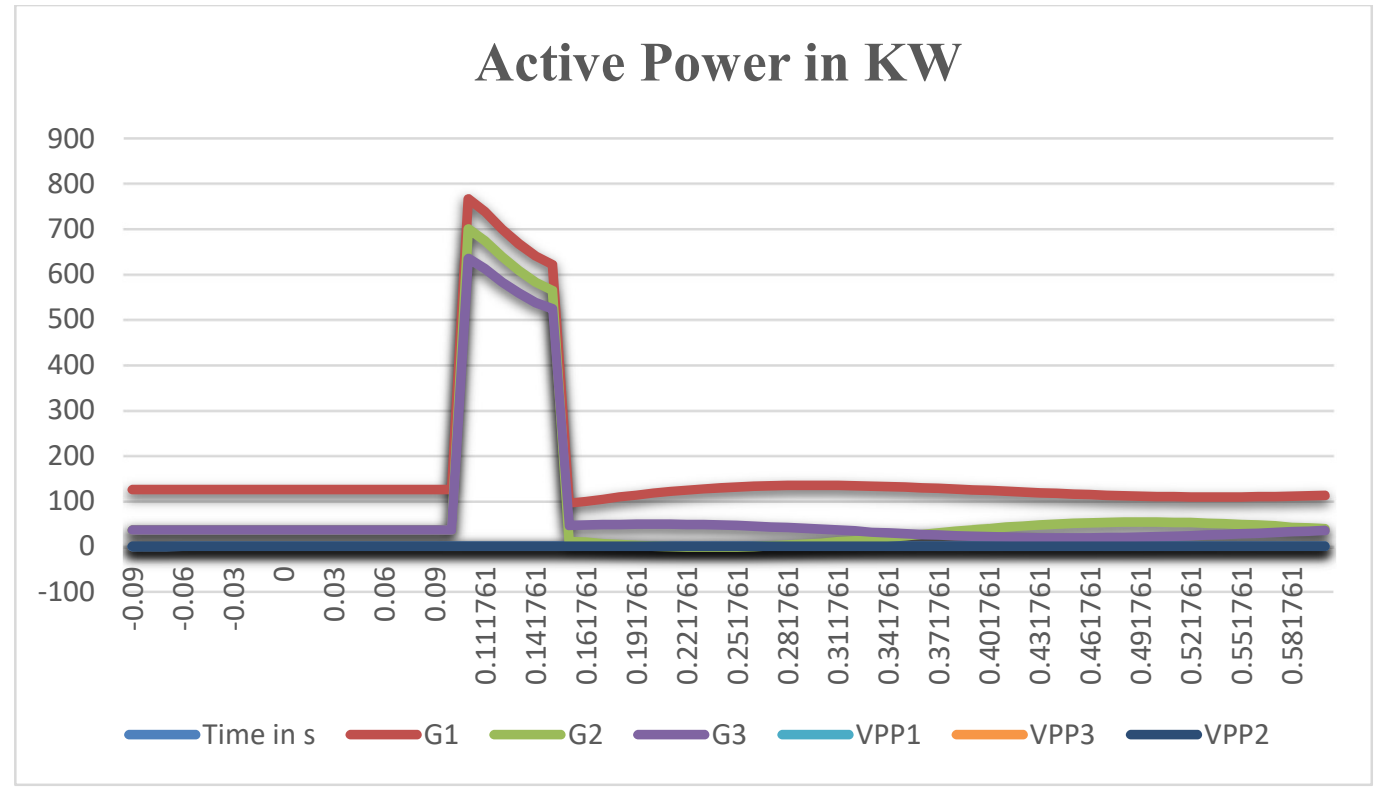

Figure 19: Active power in generators G1, G2, G3, PHOTOVOLTAIC PLANT1, PHOTOVOLTAIC PLANT2 AND PHOTOVOLTAIC PLANT3 with a $\mathrm{t}=\mathbf{0 . 6 s}$.

Power factor in Generators G1, G2, G3, Photovoltaic Plant1, Photovoltaic Plant2, Photovoltaic Plant3 with $\mathrm{t}=$ $0.6 \mathrm{~s}$ ( figure 20).

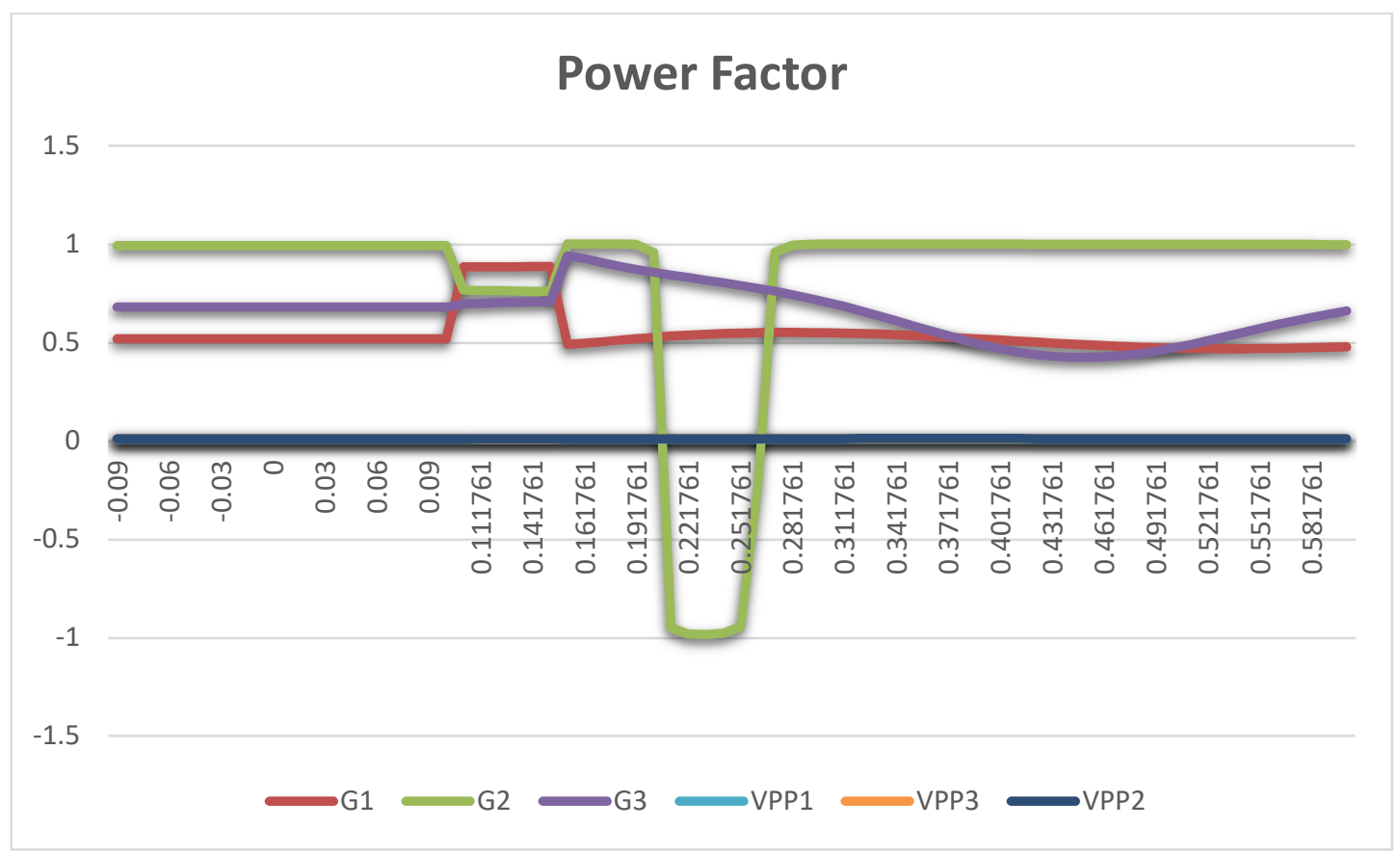

Figure 20: Power factor in Generators G1, G2, G3, Photovoltaic Plant1, Photovoltaic Plant2, Photovoltaic Plant3 with $\mathbf{t}=\mathbf{0 . 6 s}$.

Rotor angle in G2 and G3 generators at $\mathrm{t}=3 \mathrm{~s}$ ( figure 21 ). 


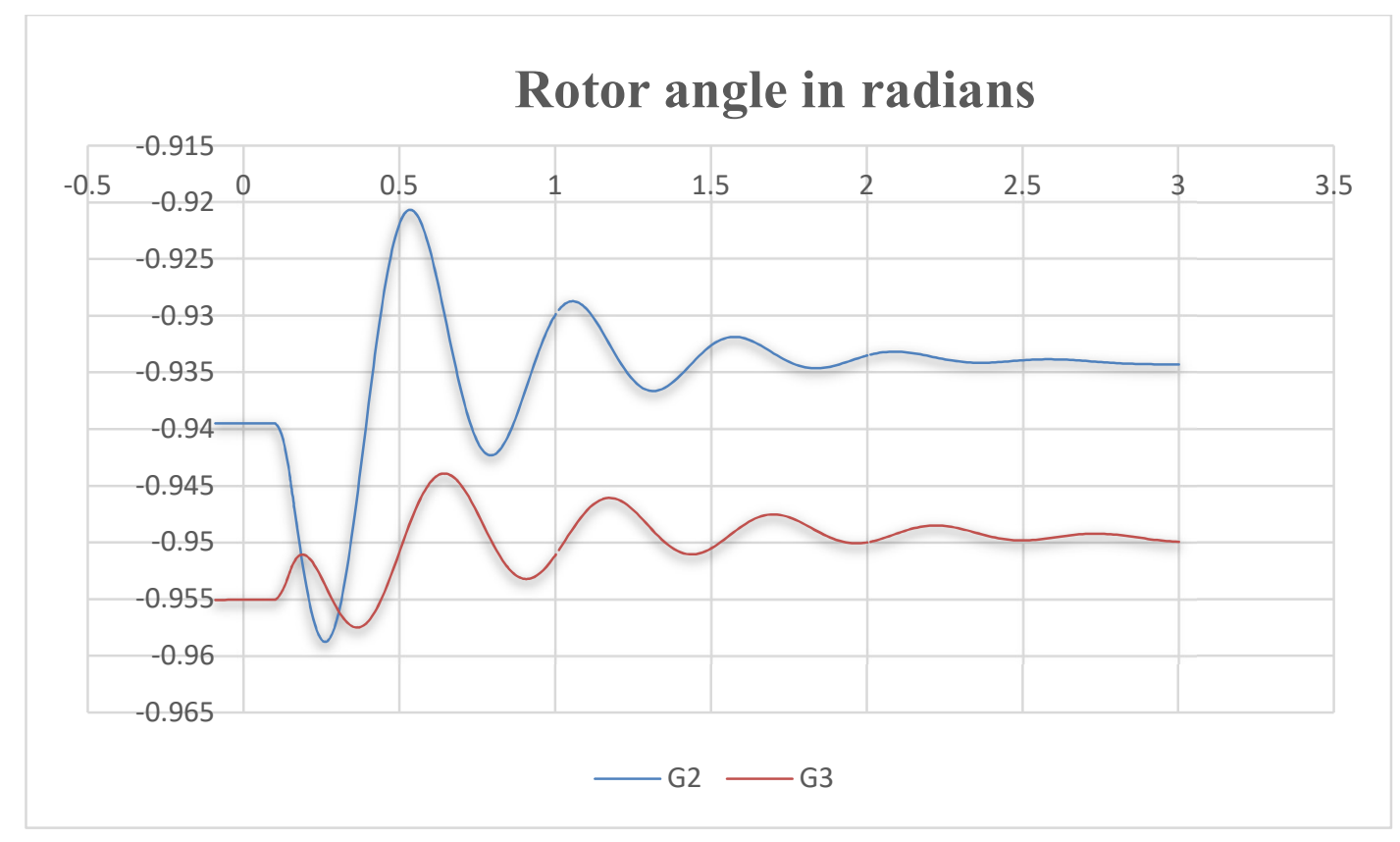

Figure 21: Angle of the rotor in the G2 and G3 generators at $t=3 s$.

\section{CONCLUSIONS}

When performing the stability analysis in the three proposed scenarios, in which the generation of energy by means of photovoltaic plants is $15 \%, 25 \%$ and $50 \%$ of the total, it is defined that in normal operating scenarios of the system the photovoltaic plants They do not affect the voltage or affect the synchronous generators present in the topology, they generate their contribution to the required voltage assuming that the generation curve of these photovoltaic plants during the day is stable and does not show drops given atmospheric conditions such as cloudiness or low radiation, without However, when faced with failures, they have a great impact on critical nodes of the system as well as on the generation nodes, in the study cases of $15 \%$ and $25 \%$ it was found that the effect on the voltage level in the generation nodes is similar to that generated by conventional generators, however in the $50 \%$ case study it is found that the voltage drop is twice per unit, and its $\mathrm{p}$ factor Power goes from inductive to capacitive, this being unacceptable since it injects all its stored energy into the system, making it much more unstable and without the possibility of recovering quickly.

The distance (and in turn the reactance) that the generation plants present to the fault node also determines their affectation, the further away a synchronous machine is, the lower its variation in the rotor angle, however, its voltage drop remains indifferent to distance and its power factor is still dependent on the response of other elements such as capacitor banks or unconventional plants.

\section{REFERENCES}

1. H. Majid Ghaffarianfar, «Voltage Stability of Low-Voltage Distribution Grid with High Penetration of Photovoltaic Power Units, » Energies, vol. 1, p. 13, 2018.

2. K. N. Hasan, «Existing approaches and trends in uncertainty modelling and probabilistic stability analysis of power systems with renewable generation, " Renewable and Sustainable Energy Reviews, vol. 101, pp. 168-180, 2019. 